\title{
Level of Diffusion and Training of Lung Ultrasound during the COVID-19 Pandemic - A National Online Italian Survey (ITALUS) from the Lung Ultrasound Working Group of the Italian Society of Anesthesia, Analgesia, Resuscitation, and Intensive Care (SIAARTI) Grad der Verbreitung und der Schulung von Lungenultraschall während der COVID-19-Pandemie - eine nationale italienische Online-Umfrage (ITALUS) der Arbeitsgruppe Lungenultraschall der Italienischen Gesellschaft für Anästhesie, Analgesie, Reanimation und Intensivmedizin (SIAARTI)
}

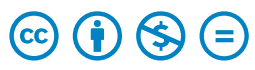

Authors

Luigi Vetrugno ${ }^{1,2}$, Francesco Mojoli ${ }^{3,4}$, Enrico Boero ${ }^{5}$, Paola Berchialla ${ }^{6}$, Elena Giovanna Bignami ${ }^{7}$, Daniele Orso ${ }^{8}$, Andrea Cortegiani ${ }^{9},{ }^{10}$, Francesco Forfori ${ }^{11}$, Francesco Corradi ${ }^{11}$, Gianmaria Cammarota ${ }^{12}$, Edoardo De Robertis ${ }^{13}$, Silvia Mongodi ${ }^{14,}{ }^{15}$, Davide Chiumello ${ }^{16}$, Daniele Poole ${ }^{17}$, Mariachiara Ippolito ${ }^{9},{ }^{10}$, Daniele Guerino Biasucci ${ }^{18}$, Paolo Persona ${ }^{19}$, Tiziana Bove ${ }^{8,2}$, Lorenzo Ball ${ }^{20}$, Paolo Pelosi ${ }^{20}$, Paolo Navalesi ${ }^{19}$, Massimo Antonelli ${ }^{18}$, Antonio Corcione ${ }^{21}$, Antonino Giarratano ${ }^{22}$, 10 , Flavia Petrini ${ }^{23}$

Affiliations

1 Department of Medicine, University of Udine, Italy

2 Department of Anesthesia and Intensive Care, University Hospital of Udine, Italy, Udine, Italy

3 Anesthesiology, Intensive Care and Pain Medicine, University of Pavia Faculty of Medicine and Surgery, Pavia, Italy

4 Anesthesia and Intensive Care, University Hospital of Pavia, Italy

5 Anesthesia and Intensive Care, Hospital Saint-Giovanni Bosco Turin, Italy

6 Department of Clinical and Biological Sciences, University of Turin Faculty of Medicine and Surgery, Torino, Italy

7 Department of Medicine and Surgery, University of Parma Department of Medicine and Surgery, Parma, Italy

8 Department of Medicine, University of Udine Department of Biological and Medical Sciences, Udine, Italy

9 Department of Surgical, Oncological and Oral Science, University of Palermo Faculty of Medicine and Surgery, Palermo, Italy

10 Department of Anesthesia Intensive Care and Emergency, University Hospital Policlinic Paolo Giaccone, Palermo, Italy

11 Department of Surgical, Medical and Molecular Pathology and Critical Care Medicine, University of Pisa School of Medicine, Pisa, Italy

12 Department of Medicine and Surgery, University of Perugia School of Medicine and Surgery, Perugia, Italy

13 Department of Medicine and Surgery, University of Perugia Department of Medicine, Perugia, Italy
14 Anesthesiology and Intensive Care, University Hospital of Pavia, Italy

15 Dipartimento di Scienze Clinico-Chirurgiche, Diagnostiche e Pediatriche, University of Pavia Faculty of Medicine and Surgery, Pavia, Italy

16 Department of Anesthesiology and Intensive Care, University of Milan, Milano, Italy

17 Anesthesia and Intensive Care Operative Unit, Hospital Saint-Martinus, Belluno, Italy

18 Department of Anesthesia and Intensive Care, University Hospital Agostino Gemelli Department of Surgical and Medical Sciences, Rome, Italy

19 UOC Anesthesia and Intensive Care Unit, University Hospital of Padua, Padua, Italy, Padua, Italy

20 Department of Anesthesia and Intensive Care, University of Genoa School of Medical and Pharmaceutical Sciences, Genova, Italy

21 Unit of Anaesthesia and intensive Care, Monaldi Hospital Naples, Italy, Naples, Italy

22 Department of Surgical, Oncological and Oral Science, University of Palermo Faculty of Medicine and Surgery, Palermo, Italy

23 Anesthesia, Intensive Care and Pain Management, President Italian Society of Anesthesia, Analgesia, Resuscitation, and Intensive Care (SIAARTI), Rome Italy, Rome, Italy

Key words

lung ultrasound, intensive care, COVID-19, SARS-CoV-2, ARDS 
received 22.02.2021

accepted 05.08.2021

published online 03.11 .2021

Bibliography

Ultraschall in Med 2022; 43: 464-472

DOI $10.1055 / a-1634-4710$

ISSN $0172-4614$

(C) 2021. The Author(s).

This is an open access article published by Thieme under the terms of the Creative Commons Attribution-NonDerivative-NonCommercial License, permitting copying and reproduction so long as the original work is given appropriate credit. Contents may not be used for commecial purposes, or adapted, remixed, transformed or built upon. (https://creativecommons.org/licenses/by-nc-nd/4.0/)

Georg Thieme Verlag KG, Rüdigerstraße 14,

70469 Stuttgart, Germany

Correspondence

Dr. Luigi Vetrugno

Department of Medicine, University of Udine, Via Colugna 50, 33100 Udine, Italy

Tel.: +39/4 32/559501

luigi.vetrugno@uniud.it

Supplementary material is available under

https://doi.org/10.1055/a-1634-4710

\section{ABSTRACT}

Purpose The goal of this survey was to describe the use and diffusion of lung ultrasound (LUS), the level of training received before and during the COVID-19 pandemic, and the clinical impact LUS has had on COVID-19 cases in intensive care units (ICU) from February 2020 to May 2020.

Materials and Methods The Italian Lung Ultrasound Survey (ITALUS) was a nationwide online survey proposed to Italian anesthesiologists and intensive care physicians carried out after the first wave of the COVID-19 pandemic. It consisted of 27 questions, both quantitative and qualitative.

Results 807 responded to the survey. The median previous LUS experience was 3 years (IQR 1.0-6.0). 473 (60.9\%) reported having attended at least one training course on LUS before the COVID-19 pandemic. 519 (73.9\%) reported knowing how to use the LUS score. 404 (52\%) reported being able to use LUS without any supervision. 479 (68.2\%) said that LUS influenced their clinical decision-making, mostly with respect to patient monitoring. During the pandemic, the median of patients daily evaluated with LUS increased 3 -fold ( $p<0.001$ ), daily use of general LUS increased from $10.4 \%$ to $28.9 \%$ $(p<0.001)$, and the daily use of LUS score in particular increased from $1.6 \%$ to $9.0 \%$ ( $<<0.001)$.

Conclusion This survey showed that LUS was already extensively used during the first wave of the COVID-19 pandemic by anesthesiologists and intensive care physicians in Italy, and then its adoption increased further. Residency programs are already progressively implementing LUS teaching. However, $76.7 \%$ of the sample did not undertake any LUS certification.

\section{ZUSAMMENFASSUNG}

Ziel Das Ziel dieser Umfrage war es, den Einsatz und die Verbreitung von Lungenultraschall (LUS), den Ausbildungstand vor und während der COVID-19-Pandemie sowie die klinische Bedeutung des LUS auf COVID-19-Fälle auf Intensivstationen (ICU) von Februar 2020 bis Mai 2020 zu beschreiben.

Material und Methoden Die „Italian Lung Ultrasound Survey“ (ITALUS) war eine landesweite Online-Umfrage, die italienischen Anästhesisten und Intensivmedizinern nach der ersten Welle der COVID-19-Pandemie unterbreitet wurde. Sie bestand aus 27 quantitativen und qualitativen Fragen.

Ergebnisse 807 Ärzte nahmen an der Umfrage teil. Die Vorerfahrung im LUS lag bei median 3 Jahren (IQR 1,0-6,0). 473 $(60,9 \%)$ gaben an, vor der COVID-19-Pandemie mindestens eine Schulung zu LUS besucht zu haben. 519 (73,9\%) gaben an, mit dem LUS-Score vertraut zu sein. 404 (52\%) gaben an, LUS ohne Aufsicht nutzen zu können. 479 (68,2\%) gaben an, dass LUS ihre klinische Entscheidungsfindung beeinflusst, vor allem in Bezug auf die Patientenüberwachung. Während der Pandemie stieg der Median der Patienten, die täglich mit LUS untersucht wurden, um das 3-Fache $(p<0,001)$, der tägliche Einsatz des allgemeinen LUS erhöhte sich von $10,4 \%$ auf $28,9 \%(p<0,001)$, und insbesondere der tägliche Einsatz des LUS-Scores stieg von 1,6\% auf 9,0\% $(p<0,001)$.

Schlussfolgerung Diese Umfrage zeigte, dass LUS bereits während der ersten Welle der COVID-19-Pandemie von Anästhesisten und Intensivmedizinern in Italien in großem Umfang eingesetzt wurde und dann weiter zugenommen hat. In der Facharztausbildung wird LUS bereits zunehmend eingeführt. Allerdings hatten in der Stichprobe 76,7\% keine LUS-Zertifizierung.

\section{Introduction}

The COVID-19 epidemic has been characterized by a high number of pneumonia cases leading to severe acute respiratory distress syndrome (ARDS) and requiring prolonged mechanical ventilation (MV) [1]. This has emphasized the demand for an easy-to-use, repeatable, bedside chest imaging modality [2]. Aside from these features, lung ultrasound (LUS) has already demonstrated higher accuracy than chest X-ray (CXR) in diagnosing several respiratory conditions, such as pneumonia, pleural effusion, and pneumothorax [3]. Thus, LUS has been implemented worldwide in both critically and non-critically ill COVID-19 patients [4-6], becoming a pivotal tool in managing COVID-19 cases, both for diagnosis and prognosis, as supported by the wealth of literature published over the last year [7-10]. Nevertheless, its role in the diagnosis, prognostication, monitoring, and follow-up of COVID-19 patients has yet to be officially acknowledged by any international scientific society. Multiple studies show a close correlation between LUS 
and CT scan findings, making them the two main imaging modalities being used during the COVID-19 pandemic [11-13]. Furthermore, while the research has produced convincing evidence on LUS adoption and usefulness in the emergency department, data from intensive care units (ICU) and perioperative settings are still scarce, especially in relation to COVID-19 patients [14, 15].

The present survey aimed to describe the extent of LUS diffusion, the level of LUS training, and the perceived clinical impact of its use on decision-making, before and after the COVID-19 pandemic, among Italian anesthesiologists and intensive care physicians.

\section{Materials and Methods}

\section{Study design and participants}

This research comprised a nationwide online survey on the use of LUS during the first wave of COVID-19. Ethical approval was not required, but consent to use the collected data was obtained (European General Data Protection Regulation, 2016/679). An e-mail invitation was sent on 24/10/2020 to 7,972 anesthesia and intensive care medicine specialists or specialty trainees who are affiliated members of SIAARTI, and by newsletter to 8070 SIAARTI affiliated and 3355 non-affiliate recipients. Personal identification codes were used to prevent multiple registrations. Data collection closed on 16/11/2020.

\section{Content and data collection}

General data about the respondents' gender, age, level of experience, and workplace were collected, followed by a series of questions on: i) the level of LUS training and experience, including residency training, number of accredited courses attended (i.e., registered courses giving continuing medical education [CME] credits) and years of practice and self-evaluated ability; ii) the clinical use of LUS, prior to and during the COVID-19 pandemic, including frequency of use, average number of patients evaluated per work shift, knowledge of the lung ultrasound score (LUS score) [16] and frequency of its application; iii) the clinical impact of LUS on decision-making, both on the extent of LUS influence on clinical decisions and opinion about the future use of LUS in diagnosis and monitoring of ARDS; iv) details about whether the respondents had undertaken a certification course and whether they completed it. Training resources used during the pandemic event were also evaluated. Wherever possible, the survey question responses were quantified using a 5-point Likert scale. The complete survey consisted of 27 questions and was conducted with the SurveyMonkey online application (Supplementary File 3).

\section{Sample size calculation and statistical analysis}

After estimating a target population of 15,000 physicians, we calculated a minimum sample size required to obtain relevant statistical power, with a $4 \%$ error margin and $95 \%$ confidence level, of 632 respondents. Details about sample size calculation are provided as Supplementary File 4.
- Table 1 Summary of respondent's characteristics.

\begin{tabular}{|c|c|c|}
\hline & $\mathbf{n}$ & $\begin{array}{l}\text { all } \\
(\mathrm{N}=807)\end{array}$ \\
\hline gender & 807 & \\
\hline female & & $426(52.8)$ \\
\hline male & & $378(46.8)$ \\
\hline not declared & & $3(0.4)$ \\
\hline age & 807 & \\
\hline median (interquartile range) & & $39.0(32.0-49.0)$ \\
\hline range & & $26.0-72.0$ \\
\hline year of specialty training conclusion & 807 & \\
\hline before 2000 & & $127(15.7)$ \\
\hline 2000-2004 & & $116(14.4)$ \\
\hline 2005-2009 & & 107 (13.3) \\
\hline 2010-2014 & & $78(9.7)$ \\
\hline 2015-2019 & & $144(17.8)$ \\
\hline resident, $5^{\text {th }}$ year & & $98(12.1)$ \\
\hline resident, $4^{\text {th }}$ year & & $22(2.7)$ \\
\hline resident, $3^{\text {rd }}$ year & & $67(8.3)$ \\
\hline resident, $2^{\text {nd }}$ year & & $23(2.9)$ \\
\hline resident, $1^{\text {st }}$ year & & $25(3.1)$ \\
\hline
\end{tabular}

Continuous variables were reported as medians plus interquartile range (IQR); binary and categorical variables were reported as numbers and percentages. Sample characteristics were summarized, and the absolute and relative response frequencies are presented in tables. The Wilcoxon test was used for paired data and the McNemar test for non-parametric distributions. Significance was set at $5 \%$. All analyses were carried out using R 4.0.0 software.

\section{Results}

\section{General characteristics}

In the period from October 24 to November 5, 2020, 807 Italian anesthesiologists and intensive care physicians responded to the survey, questions 1 to 7 , with a response rate of $5.4 \%$. The respondents' characteristics are shown in $>$ Table 1 , and their geographical distribution is shown as a percentage in $\mathbf{F i g . 1 A}$ and detailed as a bar chart in $>$ Fig. 1B.

\section{LUS training and use prior to the COVID-19 pandemic}

Questions on pre-pandemic LUS training and use (questions 8 to 13) were answered by 777 people. 473 (60.9\%) reported having attended at least one LUS training course, and 357 (45.9\%) respondents said they had received LUS teaching during their residency period. A trend of increasing use of LUS training in anesthesia and intensive care schools emerged by comparing current trainees to junior and senior specialists (respectively, who completed 


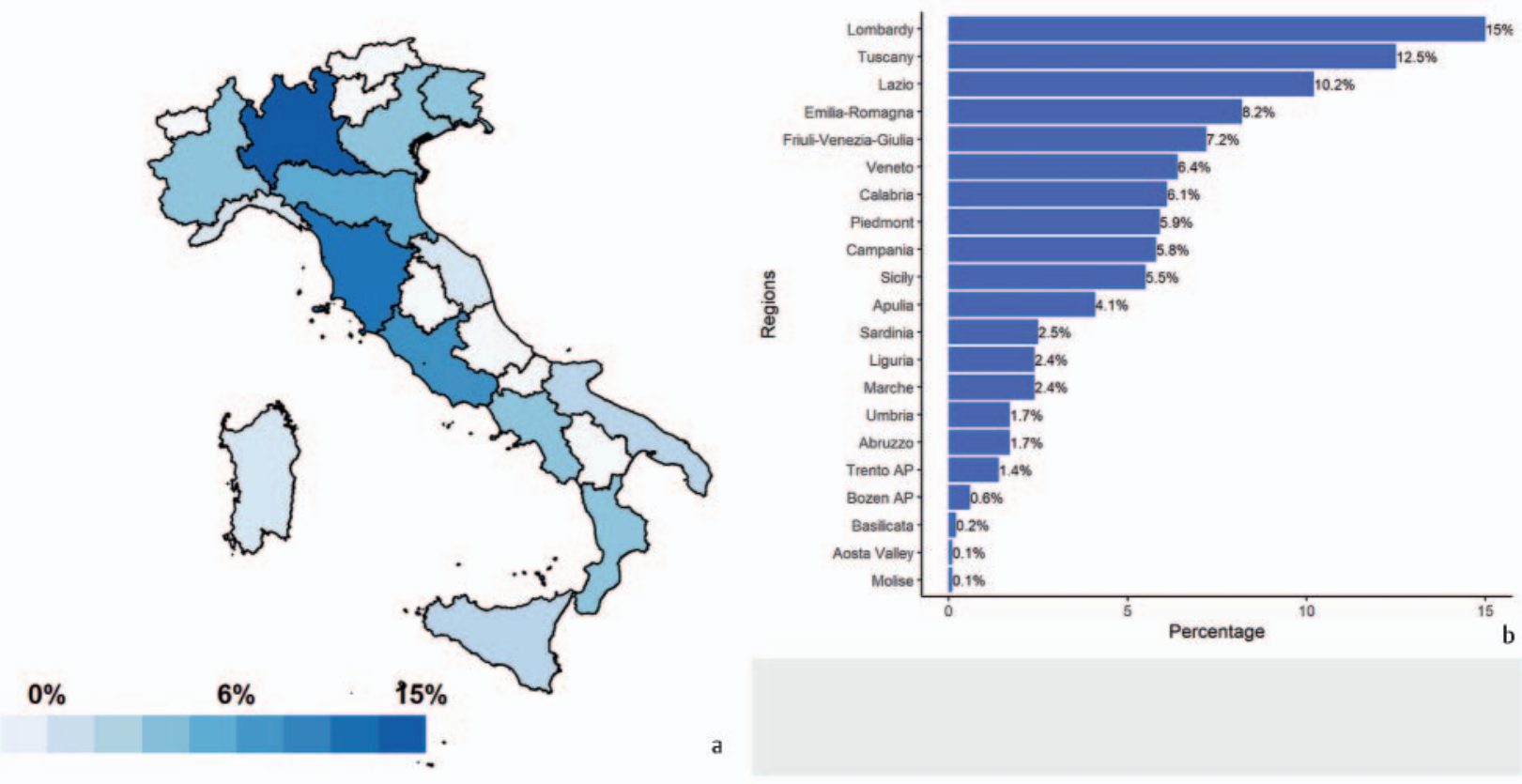

- Fig. 1 a Distribution of the respondents by geographic area. Legend: The blue gradation from $0 \%$ to $15 \%$ represents lung ultrasound utilization for each area. $\mathbf{b}$ Boxplot of the \% of Italian regions.

- Table 2 Descriptive table of lung ultrasound education and technical use.

\begin{tabular}{|c|c|c|}
\hline & $\mathbf{n}$ & all \\
\hline have you ever had a lung ultrasound course before the pandemic? & 777 & \\
\hline no & & $304(39.1)$ \\
\hline yes, one & & $255(32.8)$ \\
\hline yes, more than one & & $218(28.1)$ \\
\hline have you ever received any lung ultrasound training during specialist training? & 777 & \\
\hline yes & & $357(45.9)$ \\
\hline - number of consultants ( $\mathrm{N}, \%$ of the total) & & $174(31.6)$ \\
\hline - number of trainees ( $\mathrm{N}, \%$ of the total) & & $183(81.0)$ \\
\hline how would you define your level of knowledge of lung ultrasound? & 777 & \\
\hline 1. nonexistent or minimal & & $39(5.0)$ \\
\hline 2. mediocre, I have basic knowledge & & $168(21.6)$ \\
\hline 3. sufficient, I am able to perform with supervision & & $166(21.4)$ \\
\hline 4. good, I am able to perform without supervision & & $347(44.7)$ \\
\hline 5. excellent, I am proficient enough to teach & & $57(7.3)$ \\
\hline how many years have you been practicing lung ultrasound? & 777 & \\
\hline median (interquartile range) & & $3.0(1.0-6.0)$ \\
\hline \multicolumn{3}{|l|}{ do you know the lung ultrasound score? } \\
\hline yes & 702 & 519 (73.9) \\
\hline
\end{tabular}


- Table 3 Comparison of lung ultrasound use before and during the pandemic.

\begin{tabular}{|c|c|c|c|}
\hline & before pandemic & during pandemic & p-value \\
\hline number of patients evaluated with lung ultrasound & $N=777$ & $N=702$ & $<0.001^{1}$ \\
\hline median (IQR) & $1(1,3)^{\mathrm{a}}$ & $3(1,5)^{b}$ & \\
\hline how often did you use lung ultrasound? & $N=777$ & $N=702$ & $<0.001^{2}$ \\
\hline 1. never & $100(12.9 \%)$ & $92(13.1 \%)$ & \\
\hline 2. rarely (less than once a month) & 149 (19.2\%) & $76(10.8 \%)$ & \\
\hline 3. sometimes (less than once a week) & $170(21.9 \%)$ & $99(14.1 \%)$ & \\
\hline 4. often (more than once a week) & $277(35.6 \%)$ & $232(33.0 \%)$ & \\
\hline 5. on a daily basis (every working day) & $81(10.4 \%)$ & $203(28.9 \%)$ & \\
\hline how often did you use the LUS score? & $N=702$ & $N=702$ & $<0.001^{2}$ \\
\hline 1. never & $340(48.4 \%)$ & $241(34.3 \%)$ & \\
\hline 2. rarely (less than once a month) & $162(23.1 \%)$ & $103(14.7 \%)$ & \\
\hline 3. sometimes (less than once a week) & $120(17.1 \%)$ & $130(18.5 \%)$ & \\
\hline 4. often (more than once a week) & $69(9.8 \%)$ & $165(23.5 \%)$ & \\
\hline 5. on a daily basis (every working day) & 11 (1.6\%) & 63 (9.0\%) & \\
\hline $\begin{array}{l}{ }^{1} \text { Wilcoxon test per dati appaiati. } \\
\text { a } N=777 . \\
\text { b } N=702 \text {. } \\
{ }^{2} \text { McNemar test. }\end{array}$ & & & \\
\hline
\end{tabular}

the specialist training in the last 5 years or before, $p<0.00001$ ). Regarding the self-evaluated LUS skill level, more than half declared to be an independent provider, with 347 (44.7\%) reporting to be able to perform LUS without supervision, and 57 (7.3\%) to be able to mentor other colleagues. Only 39 (5\%) respondents said they were unable to perform LUS. The median reported length of LUS experience was 3 years (IQR 1.0-6.0). When asked if they knew what the LUS score was, 519 (73.9\%) respondents answered affirmatively ( $>$ Table 2 ).

A total of 100 (12.9\%) respondents stated they never used LUS in clinical practice prior to the onset of the pandemic, whereas $596(76.7 \%)$ reported to have used it "rarely", "sometimes", or "often". Only 81 (10.4\%) reported daily use of LUS ( $\triangleright$ Table 3 ).

Finally, $76.7 \%$ of the sample reported having never undertaken or completed a certification course in LUS (Table 5 Supplementary File).

\section{LUS training and use during and after the COVID-19 pandemic}

Questions regarding peri-pandemic use of LUS (questions 14 to 23) were answered by 702 colleagues. The survey data revealed a 3 -fold increase in the average number of patients evaluated on each shift (pre-COVID-19 median 1 [IQR 1-3] vs. COVID-19 median 3 [IQR 1-5], $p<0.001)$. The change in frequency of use varied according to the different basal degrees: non-users remained unchanged prior to and during the pandemic period $(12.9 \%$ vs. $13.1 \%$, respectively), whereas frequency of use among $86.8 \%$ of respondents increased following the pandemic's onset. In particular, the number of respondents employing LUS on a daily basis increased from $10.4 \%$ to $28.9 \%$ ( $p<0.001)$. Moreover, the LUS score entered the clinical practice of many non-users, reducing their number from 340 (48.4\%) to 241 (34.3\%), and the number of daily users of the LUS score increased from 11 (1.6\%) to 63 (9\%) $(p<0.001)(\triangleright$ Table 3$)$. With respect to LUS training, respondents reported having used different sources. Published articles were indicated by 487 (69.4\%), followed by webinars (56.1\%), and tutorials (41.5\%), while $39.7 \%$ indicated short local courses or mentoring by local experts. Only 37 (5.3\%) respondents did not refer to any training resources at all (Table 6 Supplementary data).

\section{Perceived clinical impact of LUS}

When asked about the extent to which LUS influenced clinical decision-making during the pandemic, $78(11.1 \%)$ respondents reported no influence, whereas 479 (68.2\%) reported that LUS influenced clinical decision-making "enough", "a lot”, or "extremely". Most respondents (79.3\%) stated that LUS had influenced patient monitoring the most. $94 \%$ of the respondents agreed that LUS could be used in the future for the diagnosis and monitoring of ARDS in non-COVID-19 patients ( $\triangleright$ Table 4 ). The qualitative aspects of the survey are provided as Supplementary File 2, and the word cloud generated using the sentences provided in the answers is shown in > Fig. 2. 


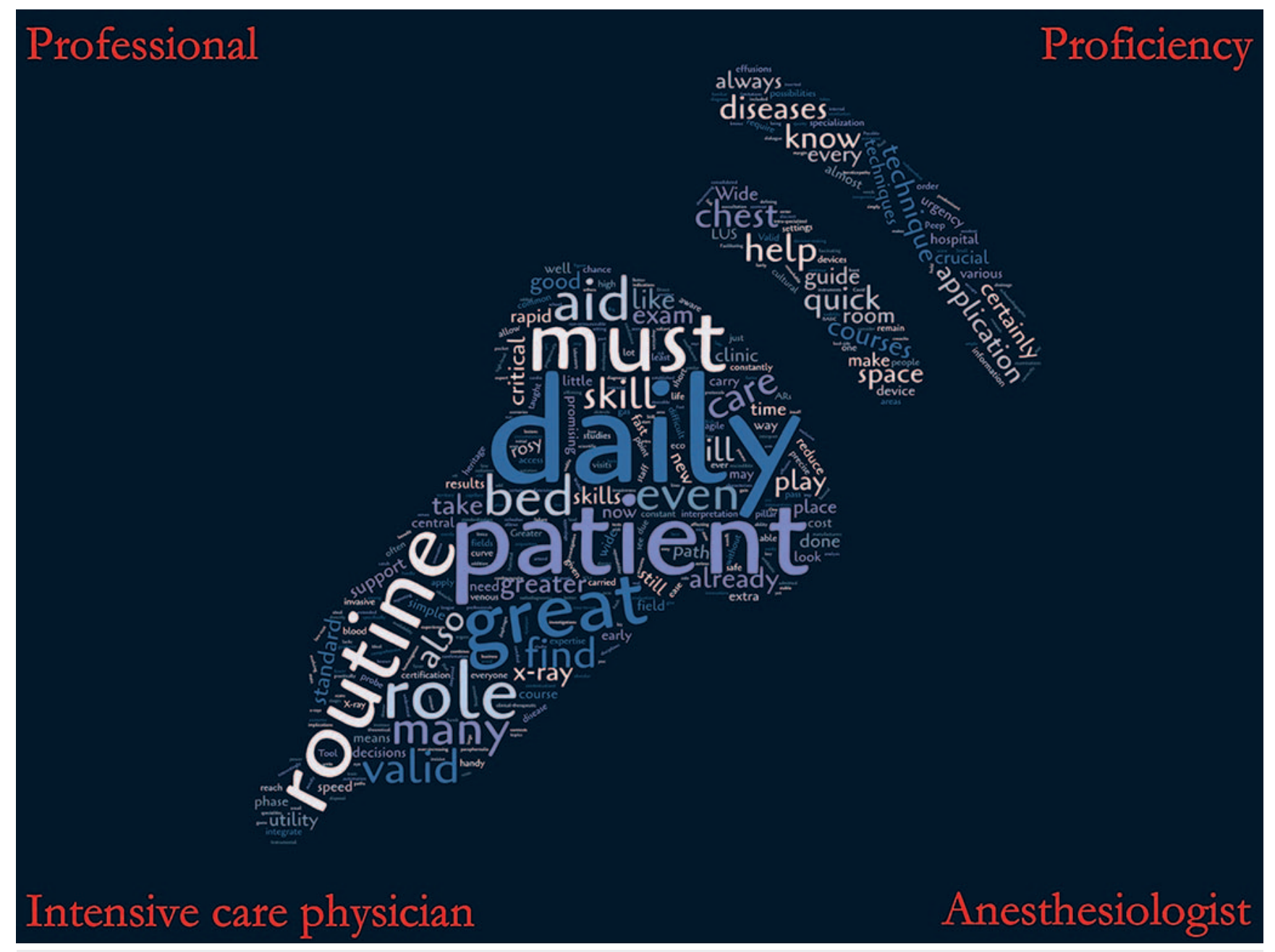

- Fig. 2 Ultrasound probe with word cloud using the words provided in the survey answers.

- Table 4 Lung Ultrasound perceived clinical impact.

\begin{tabular}{|c|c|c|}
\hline & $\mathbf{N}$ & \\
\hline how much the use of pulmonary ultrasound has affected your clinical decisions during the pandemic? & 702 & \\
\hline 1. nothing & & $78(11.1)$ \\
\hline 2. low & & $145(20.7)$ \\
\hline 3. enough & & $300(42.7)$ \\
\hline 4. A lot & & $161(22.9)$ \\
\hline 5. extremely & & $18(2.6)$ \\
\hline what do you think the lung ultrasound had the most influence on? & 702 & \\
\hline monitoring & & $557(79.3)$ \\
\hline diagnosis & & $262(37.3)$ \\
\hline changes in therapy & & 215 (30.6) \\
\hline $\begin{array}{l}\text { do you think that in the future, lung ultrasound could be used for the diagnosis and monitoring of ARDS } \\
\text { not due to COVID-19 }\end{array}$ & 702 & \\
\hline yes & & $658(93.7)$ \\
\hline
\end{tabular}




\section{Discussion}

The first main finding of this survey is that LUS use has increased among Italian anesthesiologists and intensive care physicians since the onset of the pandemic. It happened in terms of the frequency of use, number of patients scanned each work shift, and adoption of a structured scoring system, i. e., the LUS score. A second main finding is that there is an increasing trend in LUS teaching among anesthesia and intensive care schools across the country. Moreover, these professionals were able to refer to classic sources, such as current literature and experts, as well as new ones, like webinars and online tutorials. As a third point, this survey's results on the perceived clinical impact of LUS show us that the vast majority of respondents take into account LUS findings when making clinical decisions, influencing mainly patient monitoring. Curiously, although the diagnosis of COVID-19 was considered to be the most influenced aspect by only one-third of the sample, most of the respondents deemed the use of LUS plausible for the diagnosis of non-COVID-19 ARDS. This discrepancy may be explained by the general low specificity of LUS findings. In fact, lung sonography is likely able to detect the newly developed bilateral infiltrates necessary to diagnose the acute respiratory distress syndrome [17], but less accurate in addressing the specific diagnosis of COVID-19, even though some evidence shows a high correlation between LUS and RT-PCR test results [6].

Summarizing the strengths of the present survey, this is the first to evaluate exclusively Italian anesthesiologists and intensive care practitioners' knowledge and use and the clinical impact that the COVID-19 outbreak in Italy had on LUS diffusion and on clinical decision-making. Furthermore, our investigation is the first to incorporate qualitative data about LUS use with quantitative data. Finally, the described results are based on a sample greater than the minimum required to be representative of the general population of Italian intensivists and thus they may actually reflect the real scenario.

Another recent survey by the Italian discussion group, "Academy of Thoracic Ultrasound", was proposed via social media to a population of about 4000 people, obtaining a sample of 123 participants (34\% working in COVID-19 wards, $26 \%$ in COVID-free wards, $20 \%$ in the emergency department, and $31 \%$ in ICUs, as reported by the authors) [18]. Compared to our sample, their respondents had longer LUS experience (a median of 5.3 years vs. 3 years). They reported $34.9 \%$ of the sample having learned LUS recently, while adoption by never-users in our sample was minimal. Their respondents learned mostly from online materials (i. e., video tutorials and webinars, $81.4 \%$ ) and $18.6 \%$ from local courses and mentors, while in our sample published articles were the most frequent source, and we registered a greater use of local experts. However, in the Academy's sample, an average increase of $250 \%$ of daily performed exams was reported, consistently with our registered 3 -fold increase. Monitoring of patients was reported by our respondents to be the most influenced clinical aspect (79.3\%), similar to the Academy's reported data (63\%). These findings are quite consistent with those collected in our survey, suggesting the application of LUS in the intensive care environment in Italy as a recent and spreading phenomenon.
Comparing our data with another previous survey on LUS adoption in ICUs conducted by the GiViTI (Italian group for the evaluation on interventions in ICU) in 2017 [19], we can note again an increase in LUS popularity and use. We hypothesize three reasons that may explain this difference: a general trend in LUS adoption by consultants, trainees entering workplaces bringing already obtained LUS skills, and the enhancing effect of the COVID-19 pandemic, which brought a large number of patients, increasing the need for diagnostic means.

Finally, in 2013, Xirouchaki et al. reported that LUS determined changes in patient management in 119 out of 253 cases (47\%) [20]. These changes comprised a large variety of invasive interventions: chest tube placement or removal, bronchoscopy, diagnostic thoracentesis, and more. Even though this outcome is less objective and was differently assessed, these results seem to be quite consistent with ours.

An interesting finding is that up to $76.7 \%$ of the sample did not attempt to obtain any LUS certification, in contrast to the fact that $44.7 \%$ reported to be sufficiently skilled to do it alone. Other studies have highlighted physicians limits to self-assess their abilities accurately [21, 22]. In their responses to the open question about the future of LUS in anesthesia and intensive care practice, respondents frequently referred to it as a "fundamental" and "useful" tool, the use of which should be applied "daily" for "diagnosis" and "monitoring" purposes. Keeping in mind that qualitative data are more subjective and must be interpreted considering the context, we agree with these considerations and recognize that the utility of ultrasound means that LUS in particular is influenced by the correct acquisition of practical technical skills, which are difficult to acquire only by watching video tutorials and online webinars [23]. Thus, the need exists to implement professional development strategies with particular regard to LUS.

\section{Clinical implications}

Up to February 2021, SARS-CoV-2 has infected at least 2583790 individuals in Italy and 2,145 patients are still admitted to ICU [24]. ICU patients with ARDS and prolonged MV require frequent thoracic imaging and LUS reduces the number of chest $X$-rays and CT scans that patients receive $[10,25]$. Our investigation shows that Italian anesthesiologists and intensivists integrate the information gathered from LUS into the clinical evaluation process and into clinical decision-making. Use of LUS to estimate the extent of lung involvement (e. g., after intubation or before the weaning process) seems to be considered plausible by Italian anesthesiologist and intensivists, and comparative studies between LUS and CT have confirmed the strong agreement of these two means [26, 27]. Furthermore, Yang et al. argued that LUS should be the imaging technique of choice for assessing COVID-19 patients due to its sensitivity, portability, and safety [27]. Consistent with our results, ICU physicians seems to be particularly open to the use of LUS in the clinical management of critically ill COVID-19 patients $[28,29]$. Thus, the time seems to have now come to consider the full integration of LUS into the teaching programs of the anesthesia and intensive care schools, as is already the case for other medical fields, such as emergency medicine [30]. 


\section{Limitations}

The question used to calculate the sample size was chosen to ensure the largest required sample, but voluntary participation in the survey may have introduced some selection bias. Our survey was formally proposed to SIAARTI members by means of e-mail and newsletter and then eventually disseminated by word of mouth. Thus, colleagues who are not society members, as well as those less keen on informatics, may have suffered from an undercoverage bias. Furthermore, a sample self-selection is likely, since the object of this survey may have been more appealing to an ultrasound-friendly audience. All of the above-mentioned reasons may have resulted in a response rate of $5.4 \%$. Moreover, a certain amount of attrition bias (13.3\%) has been registered within the different steps of the survey. With regard to subjective outcomes, the answers to certain questions may have been over- or underestimated. Finally, the veracity of the answers is not verifiable.

\section{Conclusion}

This survey showed that LUS was extensively used and adopted during the COVID-19 pandemic by anesthesiologists and intensive care physicians in Italy and that these professionals have a strong subjective feeling regarding the clinical utility of this method. However, the data collected show a diffuse lack of in-depth knowledge of the method. Of consequence, better and more diffused training and guidance on LUS use need to be put into place within our discipline. Reassessment of our discipline's ability to establish courses, seminars, and a certification pathway should not be postponed. One part of the solution could be a consensus conference of experts to standardize LUS methods in the specific setting of intensive care, which would also require the concomitant setting up of standardized training programs. This would ensure that LUS will be used in the right way, providing the necessary support to patients in ICUs.

\section{Funding}

Samsung (Thanks to the unconditional contribution of Samsung).

\section{Conflict of interest}

Francesco Mojoli, fee for lectures (Hamilton Medical, GE Healthcare, SEDA Spa). Consultancy agreement between University of Pavia and Hamilton Medical.

Silvia Mongodi, received fees for lectures by GE healthcare, outside the present work.

\section{Acknowledgements}

The authors would like to thank the Officer, Cristina Cacciagrano, and Executive Officer, Emiliano Tizi, of the Italian Society of Anesthesia, Analgesia, Resuscitation, and Intensive Care (SIAARTI) for their helpful guidance on various technical issues during the preparation and submission of the survey.
References

[1] Grasselli G, Zangrillo A, Zanella A et al. COVID-19 Lombardy ICU Network. Baseline Characteristics and Outcomes of 1591 Patients Infected With SARS-CoV-2 Admitted to ICUs of the Lombardy Region, Italy. JAMA 2020; 323: 1574-1581. doi:10.1001/jama.2020.5394

[2] McDermott C, Daly J, Carley S. Combatting COVID-19: is ultrasound an important piece in the diagnostic puzzle? Emerg Med J 2020; 37: 644-649. doi:10.1136/emermed-2020-209721

[3] Hansell L, Milross M, Delaney A et al. Lung ultrasound has greater accuracy than conventional respiratory assessment tools for the diagnosis of pleural effusion, lung consolidation and collapse: a systematic review. J Physiother 2021; 67: 41-48. doi:10.1016/j.jphys.2020.12.002

[4] Vetrugno L, Bove T, Orso D et al. Our Italian experience using lung ultrasound for identification, grading and serial follow-up of severity of lung involvement for management of patients with COVID-19. Echocardiography 2020; 37: 625-627. doi:10.1111/echo.14664

[5] Lichter Y, Topilsky Y, Taieb P et al. Lung ultrasound predicts clinical course and outcomes in COVID-19 patients. Intensive Care Med 2020; 46: 1873-1883. doi:10.1007/s00134-020-06212-1

[6] Volpicelli G, Gargani L, Perlini S et al. Lung ultrasound for the early diagnosis of COVID-19 pneumonia: an international multicenter study. Intensive Care Med 2021; 47: 444-454. doi:10.1007/s00134-021-06373-7

[7] Zieleskiewicz L, Markarian T, Lopez A et al. AZUREA Network. Comparative study of lung ultrasound and chest computed tomography scan in the assessment of severity of confirmed COVID-19 pneumonia. Intensive Care Med 2020; 46: 1707-1713. doi:10-1007/s00134-020-06186-0

[8] Dargent A, Chatelain E, Kreitmann L. COVID-LUS study group et al. Lung ultrasound score to monitor COVID-19 pneumonia progression in patients with ARDS. PLoS One 2020; 15: e0236312 doi:10.1371/journal. pone. 0236312

[9] Boero E, Rovida S, Schreiber A et al. The COVID-19 Worsening Score (COWS) - a predictive bedside tool for critical illness. Echocardiography 2021; 38: 207-216. doi:10.1111/echo. 14962

[10] Mongodi S, Orlando A, Arisi E et al. Lung Ultrasound in Patients with Acute Respiratory Failure Reduces Conventional Imaging and Health Care Provider Exposure to COVID-19. Ultrasound Med Biol 2020; 46: 2090-2093. doi:10.1016/j.ultrasmedbio.2020.04.033

[11] Tung-Chen Y, Martí de Gracia M, Díez-Tascón A et al. Correlation between Chest Computed Tomography and Lung Ultrasonography in Patients with Coronavirus Disease 2019 (COVID-19). Ultrasound Med Biol 2020; 46: 2918-2926. doi:10.1016/j.ultrasmedbio.2020.07.003

[12] Nouvenne A, Zani MD, Milanese G et al. Lung Ultrasound in COVID-19 Pneumonia: Correlations with Chest CT on Hospital admission. Respiration 2020; 99: 617-624. doi:10.1159/000509223

[13] Vetrugno L, Baciarello M, Bignami E et al. The "pandemic" increase in lung ultrasound use in response to COVID-19: can we complement computed tomography findings? A narrative review. Ultrasound J 2020; 12: 39 doi:10.1186/s13089-020-00185-4

[14] Alhazzani W, Møller MH, Arabi YM et al. Surviving Sepsis Campaign: Guidelines on the Management of Critically III Adults with Coronavirus Disease 2019 (COVID-19). Crit Care Med 2020; 48: e440-e469. doi:10.1097/CCM.0000000000004363

[15] Cammarota G, Lauro G, Sguazzotti I et al. Esophageal Pressure Versus Gas Exchange to Set PEEP During Intraoperative Ventilation. Respir Care 2020; 65: 625-635. doi:10.4187/respcare.07238

[16] Bouhemad B, Mongodi S, Via G et al. Ultrasound for "lung monitoring" of ventilated patients. Anesthesiology 2015; 122: 437-447. doi:10.1097/ALN.0000000000000558

[17] Ferguson ND, Fan E, Camporota L et al. The Berlin definition of ARDS: an expanded rationale, justification, and supplementary material. Intensive Care Med 2012; 38: 1573-1582. doi:10.1007/s00134-012-2682-1 
[18] Zanforlin A, Tursi F. Accademia di Ecografia Toracica Group. How Is COVID-19 Changing Lung Ultrasound? A Survey by the Thoracic Ultrasound Academy. J Ultrasound Med 2021; 40: 417-418. doi:10.1002/ jum. 15398

[19] Calamai I, Greco M, Bertolini G et al. Italian Group for the Evaluation of Interventions in Intensive Care Medicine (GiViTI). Current adoption of lung ultrasound in Intensive Care Units: an Italian multi-center survey. Minerva Anestesiol 2017; 83: 720-727. doi:10.23736/S03759393.17.11509-9

[20] Xirouchaki N, Kondili E, Prinianakis G et al. Impact of lung ultrasound on clinical decision making in critically ill patients. Intensive Care Med 2014; 40: 57-65. doi:10.1007/s00134-013-3133-3

[21] Davis DA, Mazmanian PE, Fordis M et al. Accuracy of physician self-assessment compared with observed measures of competence: a systematic review. JAMA 2006; 296: 1094-102. doi:10.1001/ jama.296.9.1094

[22] Kruger J, Dunning D. Unskilled and unaware of it: how difficulties in recognizing one's own incompetence lead to inflated self-assessments. J Pers Soc Psychol 1999; 77: 1121-1134. doi:10.1037//00223514.77.6.1121

[23] Galarza L, Wong A, Malbrain MLNG. The state of critical care ultrasound training in Europe: A survey of trainers and a comparison of available accreditation programmes. Anaesthesiol Intensive Ther 2017; 49: 382386. doi:10.5603/AIT.a2017.0075
[24] https://www.agenas.gov.it/covid19/web/index.php?r=site\%2Ftab1; assessed 4 February, 2021

[25] Brogi E, Bignami E, Sidoti A et al. Could the use of bedside lung ultrasound reduce the number of chest $x$-rays in the intensive care unit? Cardiovasc Ultrasound 2017; 15: 23 doi:10.1186/s12947-017-0113-8

[26] Haaksma ME, Heldeweg MLA, Lopez Matta JE et al. Lung ultrasound findings in patients with novel SARS-CoV-2. ERJ Open Res 2020; 6: doi:10.1183/23120541.00238-2020

[27] Yang Y, Huang Y, Gao F et al. Lung ultrasonography versus chest CT in COVID-19 pneumonia: a two-centered retrospective comparison study from China. Intensive Care Med 2020; 46: 1761-1763. doi:10.1007| s00134-020-06096-1

[28] Peh WM, Ting Chan SK, Lee YL et al. Lung ultrasound in a Singapore COVID-19 intensive care unit patient and a review of its potential clinical utility in pandemic. J Ultrason 2020; 20: e154-e158. doi:10.15557/ JoU.2020.0025

[29] Koenig S, Mayo P, Volpicelli G et al. Lung Ultrasound Scanning for Respiratory Failure in Acutely III Patients: A Review. Chest 2020; 158 : 2511-2516. doi:10.1016/j.chest.2020.08.2052

[30] Ma IWY, Steinmetz P, Weerdenburg K et al. The Canadian Medical Student Ultrasound Curriculum: A Statement From the Canadian Ultrasound Consensus for Undergraduate Medical Education Group. J Ultrasound Med 2020; 39: 1279-1287. doi:10.1002/jum.15218 